Zhang, Pengfei

Han, Bing

Kuang, Haibo

http://dx.doi.org/10.21278/brod72103

ISSN 0007-215X

eISSN $1845-5859$

\title{
RISK TRANSMISSION AND CONTROL OF PORT-HINTERLAND SERVICE NETWORK: FROM THE PERSPECTIVE OF PREVENTIVE INVESTMENT AND GOVERNMENT SUBSIDIES
}

UDC 005.52:005:334:612.063

Original scientific paper

\begin{abstract}
Summary
The increase in risk prevention investments in the port-hinterland service network (PHSN) effectively enhances the network's ability to resist risks and improve the sustainability and stability of ocean transportation. Based on the construction of the PHSN risk prevention investment utility model, the equilibrium strategy, the related characteristics of each participant in the complementary networks and the complete network are analyzed. Similarly, the subsidy policy of the government under the utility maximization of the whole service network is studied. We further propose new types of subsidy strategies based on the key nodes and key groups given the resources available and the subsidy efficiency constraints imposed, while also validating the advantages of this method based on a case analysis. The results indicate that the (1) equilibrium risk prevention investment is closely related to the Katz-Bonacich centrality, network interaction intensity, cost of unit risk prevention investment and competition intensity; (2) an undifferentiated subsidy strategy cannot improve the risk prevention effectiveness of the whole network; (3) the subsidy strategy based on key nodes and key groups effectively improves the risk prevention efficiency; and (4) the subsidy strategy of key groups is superior to the subsidy strategy of key nodes. Accordingly, the results of this study provide a reference for participants and managers in the PHSN when making risk prevention investment decisions.
\end{abstract}

Key words: $\quad$ port-hinterland service network; risk prevention; network game; subsidy policy

\section{Introduction}

The port-hinterland service network (PHSN) is the link between the ports and the hinterlands, and as such, it is an important part of the entire ocean transportation process. In recent years, risk factors such as natural disasters, strikes, terrorist attacks, improper personnel operations, and epidemics have seriously affected the security of the PHSN [1,2]. For example, the outbreak of COVID-19 in 2020 impacted, to a certain degree, the global shipping and logistics industry [3], as is shown is Fig. 1, and other types of risk event are 
listed in Table 1 . The ability of the PHSN to resist risk is directly related to the sustainability and stability of the import and export cargo transportation between the ports and the hinterlands. Therefore, while it is necessary to improve the ability of the participants and the entire transport network to prevent risk by increasing the corresponding investments before the risk occurs, doing so proves to be a great challenge for both the participants and the managers in the PHSN.
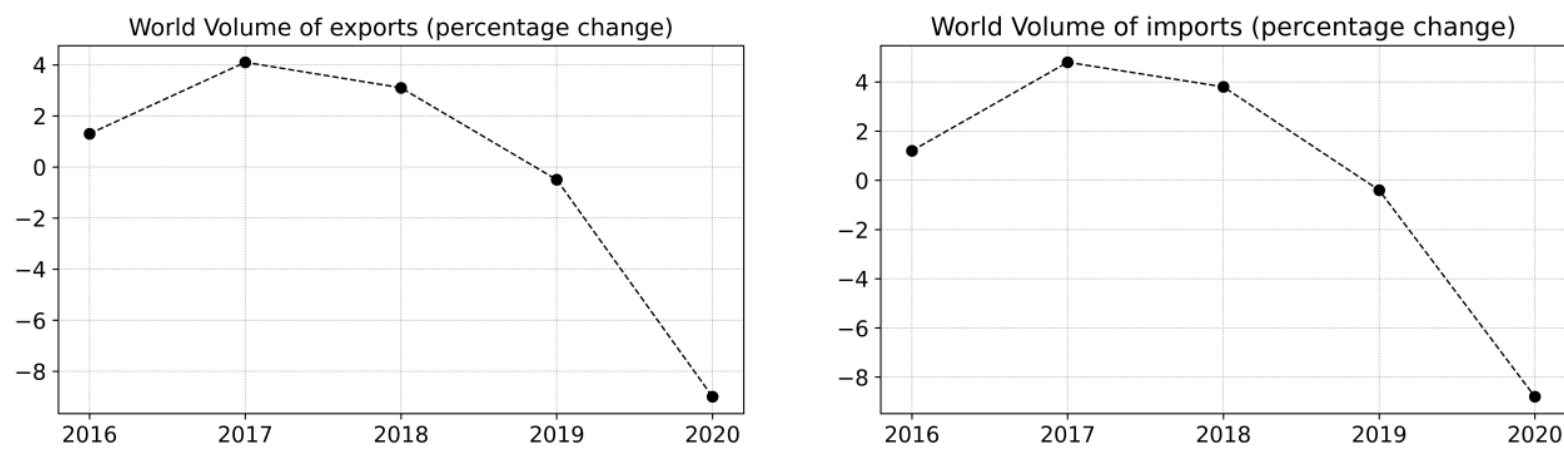

Fig. 1 Impacts of COVID-19 on world volume of exports and imports

Source: UNCTAD (2020).

Table 1 Representative risk event related with PHSNs

\begin{tabular}{|c|c|c|}
\hline Type & Event & Consequence \\
\hline \multirow{2}{*}{$\begin{array}{l}\text { Natural } \\
\text { disasters }\end{array}$} & $\begin{array}{l}\text { 2011.3, Earthquake of the } \\
\text { Pacific coast of Tōhoku, } \\
\text { Japan }\end{array}$ & $\begin{array}{l}\text { All ports in the northeastern part of Japan and the surrounding } \\
\text { hinterland facilities were closed. Seven percent of Japan's } \\
\text { containers were damaged or backlogged. }\end{array}$ \\
\hline & $\begin{array}{l}\text { 2005, Hurricane Katrina, } \\
\text { America }\end{array}$ & $\begin{array}{l}\text { USD1.7 billion damages to the Louisiana port and estimated USD } \\
882 \text { million losses of agricultural trade. }\end{array}$ \\
\hline \multirow{2}{*}{ Explosions } & $\begin{array}{l}\text { 2015.8.12, Tianjin port } \\
\text { explosion, China }\end{array}$ & $\begin{array}{l}165 \text { people were killed, } 798 \text { were injured. } 304 \text { buildings, } 12428 \text { cars } \\
\text { and } 7533 \text { containers were destroyed or damaged. The direct } \\
\text { economic loss was RMB } 6.8 \text { billion. }\end{array}$ \\
\hline & $\begin{array}{l}\text { 2020.8.4, Beirut port } \\
\text { explosion, Lebanon }\end{array}$ & $\begin{array}{l}137 \text { people were killed, } 5000 \text { were injured. The economic loss was } \\
\text { more than USD } 3 \text { billion }\end{array}$ \\
\hline \multirow{2}{*}{ Strikes } & $\begin{array}{l}2002 \text {, Port strike on US } \\
\text { west coast, America }\end{array}$ & $\begin{array}{l}\text { Ten terminals in the Port of Los Angeles and Long Beach were } \\
\text { affected. The two ports were suspended for } 5 \text { days, and the daily } \\
\text { economic loss was as high as USD } 1 \text { billion. }\end{array}$ \\
\hline & $\begin{array}{l}\text { 2017, Spanish port strikes, } \\
\text { Spain }\end{array}$ & $\begin{array}{l}\text { A large number of ships were diverted and cargo transshipped, and } \\
\text { Maersk's losses caused by this amounted to more than EUR12 } \\
\text { million. }\end{array}$ \\
\hline
\end{tabular}

Source: Summarized by the authors from various sources.

The PHSN is composed primarily of ports, intermediate carriers, and nodes in the hinterlands. In recent years, many scholars have discussed the competition and cooperation relationships among the participants of the transportation service network from the perspective of supply chain management. The research issues involve service pricing[4], strategy selection under demand, price and other uncertainties[5,6], contract formulation based on benefit maximization and an alliance strategy to enhance competitiveness[7,8]. However, risk, as an important factor affecting the stability of the transportation service network, is not fully considered. In the existing research, the risks faced by the transportation service network are reflected primarily in the identification of risk factors during the service process and participants interactions with respect to risk factors and risk assessment[9-13]. In addition, focusing on the uncertainty of demand, supply, price, and natural conditions in the 
transportation service network and on the interruption of service nodes, many scholars use stochastic programming, scenario analyses, robust optimization, and other methods to construct optimal single objective and multi-objective models based on revenue, quantity of goods, costs, transportation time and other factors[14-17] to improve the stability and efficiency of the transportation service network.

To sum up, scholars have conducted in-depth studies of the game relationship among participants, risk factor identification, and model design in transportation service networks, thus providing theoretical and technical support for solving the problems in the PHSN. However, the existing research is concerned primarily with (1) transportation service problems and the solutions to problems that follow the occurrence of risks in the supply chain, (2) a lack of consideration regarding network utility between agents in the transportation service network and (3) the adoption of precautionary measures for risks. Accordingly, this paper constructs the PHSN risk prevention investment utility model, analyzes the participants' risk prevention investment utilities and strategies from the perspective of managers and operators in the PHSN, studies the optimal subsidy strategy under a whole network utility maximization scenario, proposes the subsidy strategy based on the identification of key nodes and key groups for resource and efficiency constraints, and validates the model and method via a case analysis.

This paper is organized as follows. Section 2 briefly reviews the related literature. In Section 3, we construct the risk prevention investment utility function and analyze the equilibrium strategy and other characteristics in complementary and complete PHSNs. To investigate the subsidy policy of government in improving the risk prevention utility, two types of subsidy policies are presented in Section 4. In Section 5, we further put forward the key node and key group subsidy methods to enhance subsidy utility and efficiency. A case study validates this model in Section 6, and conclusions are presented in Section 7.

\section{Literature Review}

Here we will briefly discuss previous research that has focused on port investment under uncertainties and risk prevention, and network game studies.

(1) Port investment with uncertainties

Substantial research on port investments has been conducted, including studies on port capacity, price, route, and scale, under a variety of situations, such as regional competition, alliances, monopolies and shared hinterlands[18-22]. As uncertainty is an important risk factor that affects the stable operation of ports and transportation networks, it has gradually become the focus of scholarly research. The uncertain factors considered mainly include time, port capacity, market demand and information asymmetry. For example, Matteo Balliauw studied the problems of the time and scale of capacity investments for port managers and port operators in the face of congestion and uncertainty. The results reveal that a high proportion of public participation prompts early large-scale investments, that the amount of investment will increase with the increase of cost and uncertainty and that the investment time will simultaneously be delayed[23]. Ali Asadabadi combines stochastic programming, two-level programming and game theory to consider the optimal investment strategy of uncertain ports, such as time and port capacity under competitive and cooperative circumstances, to improve the stability and flexibility of ports[24]. Hsiao-chi Chen built a two-stage game model and analyzed the port capacity investment strategy of risk-averse ports in the face of port congestion and market uncertainty[25]. Xiaofan Lai takes into account information sharing between ports and shipping enterprises as well as the risk preferences of shipping enterprises in studies about the investment strategies of sustainable emissions reduction using a two-stage game model. The results indicate that sustainable emissions reduction investment is positively 
correlated with port service price and negatively correlated with freight[6]. These studies serve as references as ports deal with the problems of uncertainty.

(2) Risk prevention

In recent years, terrorist attacks, natural disasters, hazardous chemical explosions, and other such major issues have seriously affected ports and their related service networks. Hence, as the problem of risk response has attracted the attention of scholars, the existing literature has focused on the responses to related risk problems, including risk response and prevention. Risk response is reflected primarily in the allocation and scheduling of related resources, route planning, and timing selection after the risk occurs[26-28]. The prevention of risk involves reducing the probability of risks and enhancing the ability to resist risks by increasing investments in risk prevention. Accordingly, scholars conducted an in-depth analysis of the scale, timing, and strategy of risk prevention investments based on the characteristics of the ports' attributes, backgrounds, risk occurrence probability, and related constraints. For example, Nan Liu studied the risk prevention investment strategies of two adjacent ports under four scenarios, and the results indicated that when two ports are complementary, the risk prevention investments of the two ports in cooperation are higher than the risk prevention investments of two ports in competition[29]. Using the landlord port as the research agent, Xiao proposed a comprehensive risk prevention investment model under the premise of considering the probability of risk occurrence and the rate of return on investment. The research found that the investment time and the probability of risk occurrence are positively correlated. However, if the supervisor does not have sufficient knowledge of the risk probability, his intervention often does not produce the desired effect[30]. Liuquan Gong built a stylized analytical model to examine the managerial and policy implications of interactions between the two counteracting mechanisms. The results indicate that while port managers always prioritize capacity investment over natural disaster prevention investment, social welfare maximizing ports invest more in both capacity and disaster prevention than profit maximizing operators[31].In addition, Yi-bin Xiao proposed a comprehensive economic model to study coastal and marine disaster prevention investment and analyze the relationships between investment timing and investment amount and disaster occurrence probability and return in terms of prevention investment for marine disasters and climate change[32]. Laingo M. Randrianarisoa used two host ports as research objects and examined the optimal investment scale and investment time of ports when coping with climate change[33].

\section{(3) Network game}

Another aspect involved in our research is the network game. Ballester conducted a comprehensive analysis in 2006 that provided theoretical support for the following studies. Under the noncooperative game, he conducted an in-depth study of the optimal consumption amount, welfare utility, network conversion and importance of the participants in the consumption network[34]. Subsequently, relevant studies gradually appeared in various fields. For example, Michael D. König analyzed the Nash equilibrium strategy of complete competition among multiple enterprises in multiple markets in the R\&D network and investigated the effectiveness of the strategy and the relationship between subsidy strategy and network structure[35]. Robert W. Helsley analyzed the interaction strategies and settlement strategies of individuals in social networks while considering the network interaction utility[36]. Coralio Ballester studied the relationship between individual efforts and utility in criminal networks, and proposed relevant measures to reduce cybercrime, such as increasing investment in crime prevention, finding key criminal members and important criminal groups[37]. Based on the research of network Nash equilibrium and Bonacich centrality, Claudio J. Tessone puts forward a dynamic network generation mechanism based 
on individual centrality and analyzed the nesting phenomenon during the process of network convergence through examples[38]. These studies mainly focus on the Nash equilibrium state analysis in different kinds of network and the external effects of network utility, which provide the basic method and analysis perspective for our study.

(4) Research gaps

As pointed in the previous studies, little research is available about PHSN risk prevention and lacks the risk prevention equilibrium strategy analysis for each participant from network perspective. The government as the key risk manager whose subsidy policy has great impacts on the risk prevention results. However, the current studies only discuss whether the subsidy is useful, ignoring the effect of different subsidy strategy on risk prevention. The subsidy strategy made considering the risk prevention utility of the whole service network is also unsolved.

Therefore, to solve these abovementioned problems, this paper concentrates on the risk prevention of PHSNs from the perspective of investment and government's subsidy strategy by using the network game theory and some characteristics of the complex network theory, with the intent to provide insights for managers and operators in risk prevention under the limitation of resource and time.

\section{Model Construction and Solution}

The PHSN is composed of ports, carriers and nodes in hinterlands, such as hubs, logistics parks, and distribution centers, all of which play an important role in importing and exporting cargos. As displayed in Fig. 2, when cargos are transported from the hinterland to the port via carriers, various groups cooperate with each other to complete the transport process, even though there are competitive and cooperative relationships within the same groups. Participants in the same group may cooperate with each other to achieve a win-win situation in response to the threat of risk, such as natural disasters, strikes, terrorist attacks, improper personnel operations, and epidemics, while competing in price, service and hinterland. Therefore, the port-hinterland service network is a complete network in which competition and cooperation coexist. Since some properties and characteristics of complete networks are similar to those of complementary networks, this paper begins with complementary networks and then transitions to complete networks.

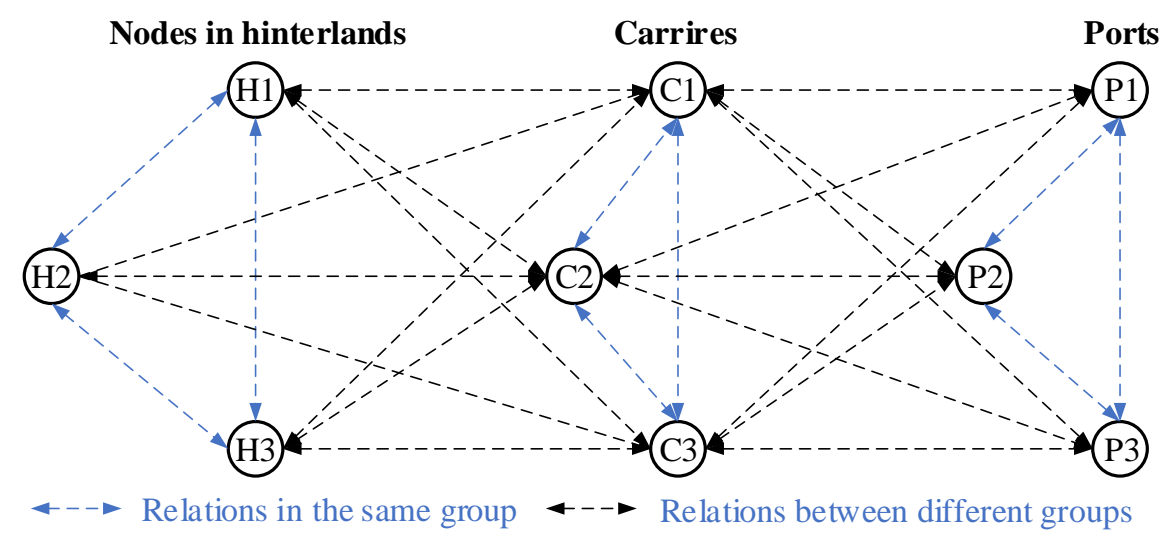

Fig. 2 Port-hinterland service network schematic diagram

\subsection{Model construction and solution under a complementary network}

In this study, we assume that the enterprise can improve its risk prevention ability by increasing its relative investment. The total risk prevention utility function of each node in the PHSN $u_{i}\left(v_{i}, v_{-i}, g\right)$ consists of two parts. The first part is $y_{i}=\beta_{i}-d_{i} v_{i}$, where $\beta_{i}$ represents 
the revenue; $d_{i}$ is the cost of per unit investment, which has positive correlation with the enterprise service ability or scale; $v_{i}$ denotes the risk prevention investment volume of participant $i$; and $v_{-i}$ is the risk prevention investment volume without participant $i$. In this way, the unlimited risk prevention investments of enterprises can be avoided. In the second part, which is the utility function of risk prevention investment, we assume diminishing returns for risk prevention utility, i.e., the next dollar invested would produce a smaller utility than the last dollar produced. This assumption is widely used in utility theory and it controls the situation of unlimited investment, which guarantees the practical meaning of this model. In the existing literatures, the linear quadratic function is widely used to consider network externality; thus, the utility function selected in this paper is:

$$
z_{i}=\alpha v_{i}-\frac{1}{2} v_{i}^{2}+\theta \sum_{j=1}^{n} g_{i j} v_{i} v_{j}
$$

and the total risk prevention utility function is:

$$
u_{i}\left(v_{i}, v_{-i}, g\right)=\beta_{i}+\left(\alpha-d_{i} v_{i}\right)-\frac{1}{2} v_{i}^{2}+\theta \sum_{j=1}^{n} g_{i j} v_{i} v_{j}
$$

Taking $\alpha_{i}=\alpha-d_{i}$ and substituting it into the arrangement, the utility function is obtained as follows:

$$
u_{i}\left(v_{i}, v_{-i}, g\right)=\beta_{i}+\alpha_{i} v_{i}-\frac{1}{2} v_{i}^{2}+\theta \sum_{j=1}^{n} g_{i j} v_{i} v_{j}
$$

Among them, $\alpha_{i}>0, g_{i j}$ is the relationship between participants $i$ and $j$, and $g_{i j} \in(0,1)$ represents the cooperative relations between participants $i$ and $j$, where higher values indicate more intense cooperation; $g_{i j} \in(-1,0)$ represents the competitive relations between participants $i$ and $j$, where the smaller values indicate greater competition; and $\theta$ is the interaction strength between participants $i$ and $j$, which reflects their coopetition frequencies. Thus, all the relations among them form a relation matrix:

$$
G=\left[\begin{array}{cccc}
g_{11} & g_{12} & \cdots & g_{1 j} \\
g_{21} & g_{22} & \cdots & g_{2 j} \\
\vdots & \vdots & \ddots & \vdots \\
g_{i 1} & g_{i 2} & \cdots & g_{i j}
\end{array}\right]
$$

Because $\frac{\partial u_{i}}{\partial v_{i}}=\alpha_{i}-v_{i}+\theta \sum_{j=1}^{n} g_{i j} v_{j}, \frac{\partial^{2} u_{i}}{\partial v_{i}^{2}}=-1$, then $u_{i}\left(v_{i}, v_{-i}, g\right)$ is a convex function. That is, as the investment increases, the utility of risk prevention decreases. $\frac{\partial^{2} u_{i}}{\partial v_{i} v_{j}}=\theta g_{i j}$; thus, if $\theta g_{i j}>0$, then $v_{i}$ and $v_{j}$ are complementary, the risk prevention utility of participant $i$ will grow with the increasing risk prevention investment of participant $j$ by network complementarity. However, if $\theta g_{i j}<0$, there exists competition between $v_{i}$ and $v_{j}$, and thus, when participant $j$ 's risk prevention utility increases, the risk prevention investment will have a negative impact on participant $i$ 's risk prevention investment utility.

Before solving the model, the Katz-Bonacich centrality of network is introduced. This network indicator is proposed by Katz and Bonacich[39], which has proven to be extremely 
useful in game theoretic applications. $\boldsymbol{G}^{k}$ is the k the power of matrix $G, k$ is the number of step, matrix $\boldsymbol{G}^{k}$ keeps track of the indirect connections in the network . Let $\boldsymbol{M}=\sum_{k=0}^{+\infty} \theta^{k} \boldsymbol{G}^{k}$, the element of this matrix, $m_{i j}=\sum_{k=0}^{+\infty} \theta^{k} g_{i j}^{[k]}$, count the number of walks of all lengths from $i$ to $j$ in the network $g, \theta$ is the decay parameter that scales down the relative weight of longer walks. Note that, when $\boldsymbol{M}$ is well-defined, one can write $\boldsymbol{M}-\boldsymbol{\theta} \boldsymbol{G M}=\boldsymbol{I}$ and hence $\boldsymbol{M}=[\boldsymbol{I}-\theta \boldsymbol{G}]^{-1}$. The Katz-Bonacich centrality of agent $i$ is $b_{i}(\mathrm{~g}, \theta)=\sum_{j=1}^{n} m_{i j}=\sum_{j=1}^{n} \sum_{k=0}^{+\infty} \theta^{k} g_{i j}^{[k]}$, which is equal to the sum of the elements of the $i$ th row of $\boldsymbol{M}$. Its matrix form is $\boldsymbol{b}(\mathrm{g}, \theta)_{n \times 1}=\mathrm{M} \mathbf{1}=[\boldsymbol{I}-\theta \boldsymbol{G}]^{-1} \mathbf{1}, \mathbf{1}$ is the $n \times 1$ dimensional vector of ones. When the weight is attached to the walks between $i$ and $j$, the weighted Katz-Bonacich centrality is:

$$
b_{\alpha_{i}}(\mathrm{~g}, \theta)=\sum_{j=1}^{n} m_{i j}=\sum_{j=1}^{n} \sum_{k=0}^{+\infty} \theta^{k} g_{i j}^{[k]} \alpha_{j}
$$

The matrix form is:

$$
\boldsymbol{b}_{\boldsymbol{\alpha}}(\mathrm{g}, \theta)_{n \times 1}=\mathrm{M} \mathbf{1}=[\boldsymbol{I}-\theta \boldsymbol{G}]^{-1} \boldsymbol{\alpha}
$$

Where $\alpha$ is a n-dimensional vector.

The first-order condition for a maximum of (3) with respect to $v_{i}$ gives the bestresponse function $v_{i}^{*}=\alpha_{i}+\theta \sum_{j=1}^{n} g_{i j} v_{j}^{*}$, The matrix form is $\boldsymbol{v}^{*}=\boldsymbol{\alpha}+\theta \boldsymbol{G} \boldsymbol{v}^{*}$, it equals $\boldsymbol{v}^{*}=[\boldsymbol{I}-\theta \boldsymbol{G}]^{-1} \boldsymbol{\alpha}$, because $\boldsymbol{M}=[\boldsymbol{I}-\theta \boldsymbol{G}]^{-1}$, so it can be rewrite to $\boldsymbol{v}^{*}=\boldsymbol{M} \boldsymbol{\alpha}$. The expanded expression is $v_{i}^{*}=\sum_{j=1}^{n} m_{i j} \alpha_{j}=\sum_{j=1}^{n} \sum_{k=0}^{+\infty} \theta^{k} g_{i j}^{[k]} \alpha_{j}$, where $\alpha_{i}=\alpha-d_{i}$.

We next provide the proof for the unique Nash equilibrium. Observe that this game is a potential game which is constructed by taking the sum of all utilities and corrected by a term which takes into account the network externalities exerted by each agent $i$ [40]. The potential function is:

$$
p(v, g, \theta)=\sum_{i=1}^{n} u_{i}(v, g)-\frac{\theta}{2} \sum_{i=1}^{n} \sum_{i=1}^{n} g_{i j} v_{i} v_{j}=\sum_{i=1}^{n} \alpha v_{i}-\frac{1}{2} \sum_{i=1}^{n} v_{i}^{2}+\frac{\theta}{2} \sum_{i=1}^{n} \sum_{i=1}^{n} g_{i j} v_{i} v_{j}
$$

Its matrix form is:

$$
\boldsymbol{p}(v, g, \theta)=\alpha \boldsymbol{v}^{T} \mathbf{1}-\frac{1}{2} \boldsymbol{v}^{T} \boldsymbol{v}+\boldsymbol{v}^{T} \frac{\theta}{2} \boldsymbol{G} \boldsymbol{v}=\alpha \boldsymbol{v}^{T} \mathbf{1}-\frac{1}{2} \boldsymbol{v}^{T}(\boldsymbol{I}-\theta \boldsymbol{G}) \boldsymbol{v}
$$

The Hessian matrix of (7) is easily computed to be $-(\boldsymbol{I}-\theta \boldsymbol{G})$. The matrix $(\boldsymbol{I}-\theta \boldsymbol{G})$ is positive definite if for all no-zero $\boldsymbol{v}$ by definition, so if $\boldsymbol{v}^{T}(\boldsymbol{I}-\theta \boldsymbol{G}) \boldsymbol{v}>0$, we can derive $\theta<\left(\frac{\boldsymbol{v}^{T} \boldsymbol{G} \boldsymbol{v}}{\boldsymbol{v}^{T} \boldsymbol{v}}\right)^{-1}$. By the Rayleigh-Ritz theorem, we have $\theta \rho(G)<1, \rho(\boldsymbol{G})$ is the spectral radius of the matrix $\boldsymbol{G}$. Thus, the necessary and sufficient condition for having a unique interior Nash equilibrium is $\theta \rho(\boldsymbol{G})<1$.

Therefore, the following conclusions can be drawn from the analysis: 
(1) If $\theta \rho(\boldsymbol{G})<1$, there exists a unique interior Nash equilibrium. At this point, the investment of agent $i$ in risk prevention is equal to its weighted Katz-Bonacich centrality, namely, $v_{i}^{*}\left(x_{i}, \boldsymbol{x}_{-i}, g\right)=b_{\alpha_{i}}(g, \theta)$. Because of the complementary effect of the network, the increase in risk prevention investment of other agents has a positive impact on risk prevention utility.

(2) If $\theta \rho(\boldsymbol{G})<1, v_{i}^{*}\left(x_{i}, \boldsymbol{x}_{-i}, g\right)$ grows as the intensity of the network interaction intensity coefficient $\theta$ increases. Since $\alpha_{i}=\alpha-d_{i}, v_{i}^{*}\left(x_{i}, x_{-i}, g\right)$ decreases with the increase in the unit cost of risk prevention investment $d_{i}$.

$$
V^{*}(g)=\sum_{i=1}^{n} v_{i}^{*}\left(x_{i}, \boldsymbol{x}_{-i}, g\right)=\sum_{i=1}^{n} b_{\alpha_{i}}(g, \theta) \text { represents the total amount of risk prevention }
$$

investment under the equilibrium state of the PHSN. Assuming that network $g$ is a nested network in network $g^{\prime}$, i.e., the density of network $g^{\prime}$ is greater than the density of network $g$, then $V^{*}\left(g^{\prime}\right)>V^{*}(g)$ due to the complementary effect of the network. Thus, it can be concluded that

(3) For a sufficiently small $\theta$, the total amount of the PHSN risk prevention investment in the equilibrium condition increases as the density of the network increases.

\subsection{Complete Network Characteristics Analysis}

In reality, the PHSN is composed of cooperative relationships and competitive relationships, i.e., it is a complete network. Let the matrix $\Sigma=\left[\sigma_{i j}\right]$ represent a complete network. According to Ballester's research[34], any complete network can be decomposed into:

$$
\Sigma=-\beta I-\gamma U+\lambda G
$$

where $I$ denotes the n-square identity matrix; $U$ denotes the n-square matrix of ones; $G=\left[g_{i j}\right]$ is a zero-diagonal nonnegative square matrix, interpreted as the adjacency matrix of the network $g$; and $g_{i j}=\left(\sigma_{i j}+\gamma\right) / \lambda, \lambda=\bar{\sigma}+\gamma, \gamma=-\min \{\underline{\sigma}, 0\}, \quad \underline{\sigma}=\min \left\{\sigma_{i j} \mid i \neq j\right\}$, $\bar{\sigma}=\max \left\{\sigma_{i j} \mid i \neq j\right\}, \sigma=-\beta-\gamma, \sigma<\min \{\underline{\sigma}, 0\}$. Because $g_{i i}=0$, a complete network can be converted into a complementary network.

$$
G^{\prime}=\left[\begin{array}{cccc}
\frac{\gamma}{\lambda} & \frac{\gamma+g_{12}}{\lambda} & \ldots & \frac{\gamma+g_{1 j}}{\lambda} \\
\frac{\gamma}{\lambda} g_{21} & \frac{\gamma}{\lambda} & \ldots & \frac{\gamma+g_{2 j}}{\lambda} \\
\vdots & \vdots & \ddots & \vdots \\
\frac{\gamma+g_{i 1}}{\lambda} & \frac{\gamma+g_{i 2}}{\lambda} & \ldots & \frac{\gamma}{\lambda}
\end{array}\right]
$$

According to the above analysis, the optimal risk prevention investment of each participant in the complementary network is $\boldsymbol{b}_{\boldsymbol{\alpha}}(\mathrm{g}, \theta)_{n \times 1}=\mathrm{M} \mathbf{1}=[\boldsymbol{I}-\theta \boldsymbol{G}]^{-1} \boldsymbol{\alpha}$, where $\boldsymbol{\alpha}$ is the n-dimensional vector. If we transform the complete network $G$ into a complementary network $G^{\prime}$, the optimal risk prevention investment of each participant in the complete network is:

$$
\boldsymbol{b}_{\alpha}(\mathrm{g}, \theta)_{n \times 1}=\mathrm{M} \mathbf{1}=\left[\boldsymbol{I}-\theta \frac{1}{\lambda} \boldsymbol{G}^{\prime \prime}\right]^{-1} \boldsymbol{\alpha}
$$


Thus, conclusion (4) states that that when $\alpha$ remains unchanged, the optimal risk prevention investment of each participant is positively correlated with the maximum competitive intensity in the PHSN. Other properties of the complete PHSN are the same as those of the complementary network in conclusions (1), (2) and (3).

\section{The subsidy strategy under overall utility maximization}

If the manager and operator of the PHSN adopt corresponding subsidy strategies, doing so can spur the PHSN participants to prevent risks and promote the ability of risk prevention for the whole network to some extent. From a macro perspective, subsidy strategies can be divided into homogeneous and targeted subsidies.

\subsection{Homogeneous risk prevention investment subsidy}

The risk prevention investment utility function of each agent is $u_{i}\left(v_{i}, v_{-i}, g\right)=\beta_{i}+\alpha_{i} v_{i}-\frac{1}{2} v_{i}^{2}+\theta \sum_{j=1}^{n} g_{i j} v_{i} v_{j}$ and $\alpha_{i}=\alpha-d_{i} x_{i}$ when assuming that the amount of subsidy for each unit of risk prevention investment is $s$. Thus, the risk prevention investment utility function of each agent after the subsidy is:

$$
u_{i}\left(v_{i}, v_{-i}, g\right)=\beta_{i}+\alpha_{i} v_{i}-\frac{1}{2} v_{i}^{2}+\theta \sum_{j=1}^{n} g_{i j} v_{i} v_{j}+s v_{i}
$$

Hence, $\frac{\partial u_{i}}{\partial v_{i}}=\alpha_{i}-v_{i}+\theta \sum_{j=1}^{n} g_{i j} v_{j}+s$. Setting $\frac{\partial u_{i}}{\partial v_{i}}=0$ yields an equilibrium risk prevention investment of $v_{i}^{*}=\alpha_{i}+\theta \sum_{j=1}^{n} g_{i j} v_{j}^{*}+s$.

The total risk prevention investment utility of the PHSN is:

$$
w=\sum_{i=1}^{n}\left(\beta_{i}+\alpha_{i} v_{i}-\frac{1}{2} v_{i}^{2}\right)+\theta \sum_{i=1}^{n} \sum_{j=1}^{n} g_{i j} v_{i} v_{j}+s \sum_{i=1}^{n} v_{i}-s \sum_{i=1}^{n} v_{i}
$$

Simplifying (13), the results is $w=\sum_{i=1}^{n}\left(\beta_{i}+\alpha_{i} v_{i}-\frac{1}{2} v_{i}^{2}\right)+\theta \sum_{i=1}^{n} \sum_{j=1}^{n} g_{i j} v_{i} v_{j}$. We then substitute $v_{i}^{*}=\alpha_{i}+\theta \sum_{j=1}^{n} g_{i j} v_{j}^{*}+s$ into (13) and differentiate $w$ with respect to $s$. It is straightforward that $\frac{\partial w}{\partial s}=\sum_{i=1}^{n} s=0$. Accordingly, it is evident that taking the homogeneous risk prevention investment subsidy cannot improve the total utility of the network.

\subsection{Targeted risk prevention investment subsidy}

When taking the targeted risk prevention investment subsidy, we assume that the subsidy for each unit of risk prevention investment is $s_{i}$ and that the utility function after the targeted risk prevention investment subsidy for each participant is:

$$
u_{i}\left(v_{i}, v_{-i}, g\right)=\beta_{i}+\alpha_{i} v_{i}-\frac{1}{2} v_{i}^{2}+\theta \sum_{j=1}^{n} g_{i j} v_{i} v_{j}+s_{i} v_{i}
$$

Thus, the risk prevention investment utility of the entire PHSN is: 


$$
w=\sum_{i=1}^{n}\left(\beta_{i}+\left(\alpha_{i}+s_{i}\right) v_{i}-\frac{1}{2} v_{i}^{2}\right)+\theta \sum_{i=1}^{n} \sum_{j=1}^{n} g_{i j} v_{i} v_{j}-\sum_{i=1}^{n} s_{i} v_{i}
$$

Let $\varphi\left(v_{i}\right)=\sum_{i=1}^{n}\left(\beta_{i}+\alpha_{i} v_{i}-\frac{1}{2} v_{i}^{2}\right)+\theta \sum_{i=1}^{n} \sum_{j=1}^{n} g_{i j} v_{i} v_{j} \quad$. It is then determined that $\frac{\partial \varphi\left(v_{i}\right)}{\partial v_{i}}=\alpha_{i}-v_{i}+\theta \sum_{j=1}^{n} g_{i j} v_{j}+\theta \sum_{j=1}^{n} g_{j i} v_{j}$. We set $\frac{\partial \varphi\left(v_{i}\right)}{\partial v_{i}}=0$ because $g_{j i}=g_{i j}$. Therefore, $\left(\alpha_{i}+s_{i}\right)-v_{i}+2 \theta \sum_{j=1}^{n} g_{i j} v_{j}=0$ and $v_{i}^{*}=\alpha_{i}+\theta \sum_{j=1}^{n} g_{i j} v_{j}$. This yields the following:

$$
v_{i}^{\prime}=\alpha_{i}+2 \theta \sum_{j=1}^{n} g_{i j} v_{j}=v_{i}^{*}+\theta \sum_{j=1}^{n} g_{i j} v_{j}
$$

It is then computed that the optimal subsidy amount for each participant is $s_{i}^{*}=\theta \sum_{j=1}^{n} g_{i j} v_{j}$. Accordingly, it is concluded that the managers and operators of the PHSN can improve the risk resistance ability of the entire service network by adopting targeted subsidies for all participants within the resource constraint.

\section{Risk prevention investment subsidy strategy under resource and efficiency constraints}

Although a targeted subsidy strategy for all participants can improve the total utility of the entire PHSN, this approach is restricted under resource and efficiency constraints. Therefore, to improve the utility and efficiency of resources, the importance of the participants in the PHSN is evaluated to determine the key nodes and groups and to implement a targeted risk prevention investment subsidy to exploit the best uses of the resources. Herein, we describe the method applied to identify the key nodes and then explain the method employed to find the key groups.

\subsection{Risk prevention investment subsidies based on key nodes}

Based on the previously discussed analysis, the optimal equilibrium investment of each participant under overall utility maximization is $v_{i}^{\prime}=\alpha_{i}+2 \theta \sum_{j=1}^{n} g_{i j} v_{j}$, and the equilibrium aggregate risk prevention investment is $v(g, \theta)=\mathbf{1}^{T} \boldsymbol{v}^{\prime}$, when assuming that the manager or operator of this PHSN can eliminate participant $i$ from network $g$. By eliminating participant $i$, the original service network changes its shape as all the direct links in $g$ stemming from $i$ also disappear. $g^{-i}$ represents the resulting network and $v\left(g^{-i}, \theta\right)$ denotes the resulting overall risk prevention investment in equilibrium state. The problem with identifying the key nodes is that when this service network achieves the maximum utility after removing participant $i$, the aggregate amount of the equilibrium risk prevention investment only reaches the minimum amount, specifically:

$$
\max \left\{v(g, \theta)-v\left(g^{-i}, \theta\right) \mid i=1, \ldots, n\right\}, \min \left\{v\left(g^{-i}, \theta\right) \mid i=1, \ldots, n\right\}
$$

Because $\boldsymbol{v}^{\prime}=[\boldsymbol{I}-2 \theta \boldsymbol{G}]^{-1} \boldsymbol{\alpha}$, the problem is further converted by solving $\min \left\{\boldsymbol{b}_{\alpha}\left(g^{-i}, \theta\right)_{n \times 1} \mid i=1, \ldots, n\right\}$. 
Because $b_{i}^{k}(g, \theta)=\sum_{j=1}^{n} g_{i j}^{k} \alpha_{j}$ and $b_{i}(g, \theta)=\sum_{k=1}^{n} \theta^{k} b_{i}^{k}(g, \theta), b_{i j}^{k}(g, \theta)=\sum_{p=1}^{k} g_{i j}^{p} b_{i}^{k-p}(g, \theta)$ and $g_{i j}^{p} b_{i}^{k-p}(g, \theta)$ are equal to the number of paths of length $k$ that start from $i$ and cross through $j$ after $p$ links. By definition, $b_{i j}(g, \theta)=\sum_{k=1}^{+\infty} \theta^{k} b_{i j}^{k}(g, \theta)$ is rewritten as $b_{i j}(g, \theta)=b_{i}(g, \theta)-b_{i}\left(g^{-j}, \theta\right)$, which indicates that the contribution of node $j$ to the centrality of node $i$ is equal to the difference of node $i$ 's centrality in $g$ and in $g^{-j}$, where node $j$ has been removed. Finally, the inter-centrality is written as follows:

$$
\delta_{i}(g, \theta)=b_{i}(g, \theta)+\sum_{j=1, j \neq i}^{n} b_{j i}(g, \theta)
$$

The interaction centrality consists of two parts. The first part is the centrality of node $i$, and the second part is the contribution of node $i$ to the centrality of every other node. From this, it is concluded that when $\delta_{i}^{*}(g, \theta) \geq \delta_{i}(g, \theta), i=1, \ldots, n$ where node $i$ is the key node.

The following is a comparison between a random node subsidy stratify and the key node subsidy strategy. Because $b_{j i}(g, \theta)=b_{j}(g, \theta)-b_{j}\left(g^{-i}, \theta\right) \quad, \quad$ then $b_{j}\left(g^{-i}, \theta\right)=b_{j}(g, \theta)-b_{j i}(g, \theta)$. This can then be written as:

$$
\begin{aligned}
& b\left(g^{-i}, \theta\right)=\sum_{j=1, j \neq i}^{n} b_{j}\left(g^{-i}, \theta\right)=\sum_{j=1, j \neq i}^{n} b_{j}(g, \theta)-\sum_{j=1, j \neq i}^{n} b_{j i}(g, \theta) \\
& =\sum_{j=1, j \neq i}^{n} b_{j}(g, \theta)-\delta_{i}(g, \theta)+b_{i}(g, \theta)=b(g, \theta)-\delta_{i}(g, \theta)
\end{aligned}
$$

Substituting (17) into the following equation yields the following:

$$
\gamma_{i}(g, \theta)=n \frac{v(g, \theta)-v\left(g^{-i}, \theta\right)}{\sum_{j=1}^{n} v(g, \theta)-v\left(g^{-j}, \theta\right)}=n \frac{b(g, \theta)-b(g, \theta)+\delta_{i}(g, \theta)}{\sum_{j=1}^{n} b(g, \theta)-b(g, \theta)+\delta_{j}(g, \theta)}=\frac{\delta_{i}(g, \theta)}{\bar{\delta}_{i}(g, \theta)} \geq 1
$$

Hence, it is clear that the key node subsidy is superior to the random node subsidy.

\subsection{Risk prevention investment subsidies based on key groups}

In the case of limited risk prevention resources, key node subsidy and key group subsidy can also be taken. Based on the concept of finding the key nodes, we characterize the method of searching for key groups. This problem can be transformed into the following:

$$
\max \left\{v(g, \theta)-v\left(g^{-S}, \theta\right)|S \subset N,| S \mid=s\right\}, \min \left\{b\left(g^{-S}, \theta\right)|S \subset N,| S \mid=s\right\}
$$

(1) When $s=1$, calculate the minimum value of $b\left(g^{-i}, \theta\right)=b(g, \theta)-\delta_{i}(g, \theta)$ to determine the maximum value of $\delta_{i}(g, \theta)$.

(2) When $s \geq 2$, determine the minimum value of the following formula:

$$
b\left(g^{-S}, \theta\right)=b(g, \theta)-\left(\delta_{i_{1}}(g, \theta)+\delta_{i_{2}}\left(g^{-i_{1}}, \theta\right)+\delta_{i_{3}}\left(g^{-i_{1}-i_{2}}, \theta\right)+, \ldots,+\delta_{i_{s}}\left(g^{-i_{1}-i_{2}-, \ldots,-i_{s-1}}, \theta\right)\right)
$$

This is equivalent to:

$$
\max \left\{\delta_{i_{1}}(g, \theta)+\delta_{i_{2}}\left(g^{-i_{1}}, \theta\right)+\delta_{i_{3}}\left(g^{-i_{1}-i_{2}}, \theta\right)+, \ldots,+\delta_{i_{s}}\left(g^{-i_{1}-i_{2}-, \ldots,-i_{s-1}}, \theta\right) \mid\left\{i_{1}, i_{2}, \ldots, i_{s}\right\} \subseteq N\right\}
$$


Then, set $b_{i, S}(g, \theta)=\sum_{k \geq|S|} \theta^{k} b_{i, S}^{k}(g, \theta), i \notin S$, which reflects the contribution of group $S$ to the centrality of any participant outside the set $S . b_{i, S}^{k}(g, \theta)$ calculates the number of paths for length $k$ starting from $i$ and passing through all nodes in $S$ at least once. $b_{i, S}^{k}(g, \theta)=\sum_{j \in S} \sum_{p=1}^{k} g_{i j}^{p} b_{j, S-\{j\}}^{k-p}(g, \theta) \quad, \quad$ when $S=\varnothing \quad$ the $\quad$ result $\quad$ is $\quad b_{i, \varnothing}(g, \theta)=b_{i}(g, \theta)$. $\lambda_{S}(g, \theta)=\sum_{i \in S} b_{i, S \backslash\{i\}}(g, \theta)+\sum_{i \in S} b_{i, S}(g, \theta)$ adds up the walks stemming from nodes outside the set and those starting from nodes inside the set. When focusing on singletons, we get $\lambda_{i}(g, \theta)=\delta_{i}(g, \theta)$. Therefore, the inter-centrality of group $S$ is as follows:

(1) When $|S|=1$, the group inter-centrality equals the inter-centrality $\delta_{i}(g, \theta)$.

(2) When $|S|>1$, the inter-centrality of group $S$ is:

$$
\delta_{S}=\delta_{i_{1}}(g, \theta)+\delta_{i_{2}}\left(g^{-i_{1}}, \theta\right)+\delta_{i_{3}}\left(g^{-i_{1}-i_{2}}, \theta\right)+, \ldots,+\delta_{i_{s}}\left(g^{-i_{1}-i_{2}-, \ldots,-i_{s-1}}, \theta\right)
$$

Therefore, if $S^{*}$ is a group with the highest group inter-centrality, group $S^{*}$ is the key group, i.e., $S^{*} \in \arg \max \left\{\delta_{S}(g, \theta)|S \subset N| S \mid,=\mathrm{s}\right\}, \quad 1 \leq s \leq n-1$.

\section{Case Analysis}

This study analyzes the agents' risk prevention investment strategy and its characteristics from the network perspective and advances several subsidy strategies. We select a PHSN in northeast China as an example to illustrate the results. Consider a PHSN with 35 cities as nodes in the hinterland, 85 registered logistics enterprises as carriers and 6 ports in the provinces of Liaoning, Jilin and Heilongjiang. The port group consists of Dalian Port, Dandong Port, Yingkou Port, Panjin Port, Jinzhou Port and Huludao Port. The relevant data of the ports, carriers and nodes in hinterlands from 2020 are retrieved from the Yearbook Ports of China, China Logistics Yearbook, and Northeastern China Statistical Yearbook. As the PHSN is a complete network that consists of cooperative and competitive relations between each node, we use a multinomial logit model and gravity model to compute the cooperative and competitive relations, respectively. A multinomial logit model is used to describe the choice probability between two agents. Its basic expression is $p_{i}=\frac{\exp \left(b v_{i}\right)}{\sum_{i=1}^{n} \exp \left(b v_{i}\right)}=\frac{1}{1+\sum_{i \neq j} \exp \left[b\left(v_{i}-v_{j}\right)\right]}$, where $v$ denotes the utility of each agent, $b$ is a constant above zero, and the gravity model is used to compute the volumes of goods between two places. The basic formula is $T_{i j}=\frac{\alpha p_{i} p_{j}}{d_{i j}^{2}}$, where $p_{i}$ and $p_{j}$ represent the export volume of goods between the two places and $d_{i j}$ is the distance between the two places. To simplify the model, let $\alpha=1$. The indicators considered in computing the cooperative relations between nodes in the hinterland and the carriers are registered capital, number of employees, number of years since the establishment of the company, ownership of company, i.e., person, other company or country, the distance between the carrier and the port, and the distance to the carrier. Because the choice probabilities of nodes in the hinterland can affect the carriers' choice probabilities, the relations between carriers and ports are the product of the choice probability between nodes in the hinterlands and that between carriers and ports. For the 
choice probabilities between nodes in the hinterlands and port and that between carriers and ports, indicators include such factors as distance, the number of berth, port throughput, average ship loading and uploading capacity per hour, average drawbridge loading and uploading capacity per hour, number of arrived ships, and average number days of containers are delayed in the yard. Because Dalian Port and Yingkou Port belong to the Liaoning Port Group, the relations between them are calculated using the multinomial logit model. Finally, to reduce the volatility of the data analysis, we standardize the data, a $126 \times 126$ matrix of a PHSN is obtained, as presented in Fig. 3 and Table 2.

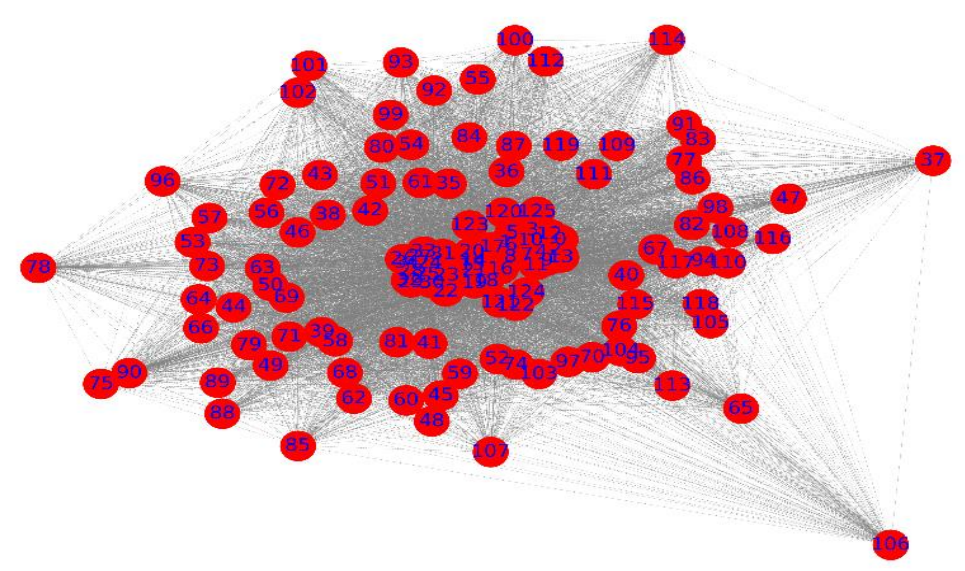

Fig. 3 The PHSN of three provinces in northeast China

Table 2 Statistical table of the nodes in the PHSN

\begin{tabular}{|l|l|c|}
\hline Ports & $\begin{array}{l}\text { Dalian Port, Yingkou Port, Dandong Port, Jinzhou Port, } \\
\text { Huludao Port, Panjin Port }\end{array}$ & 6 \\
\hline Carriers & $\begin{array}{l}\text { CRCT, China materials storage and transportation group } \\
\text { JC TRANS、CIMC LOGISTICS, Dalian CRFS, REC...... }\end{array}$ & 85 \\
\hline $\begin{array}{l}\text { Nodes in } \\
\text { hinterlands }\end{array}$ & $\begin{array}{l}\text { Shenyang, Dalian, Changchun, Haerbin, Yingkou, Anshan, } \\
\text { Siping...... }\end{array}$ & 35 \\
\hline
\end{tabular}

(1) The validation of the conclusions in Section 3. The maximum eigenvalue of the network is 77.723. Since the existence condition of the equilibrium solution is $\theta \rho(\boldsymbol{G})<1$, then $\theta<0.01287$. We set $\theta=0.012$ in the following analysis without special instructions. Using ports as an example, their equilibrium risk prevention investment, which is presented in Table 3, has a value that is equal to the port's weighted Katz-Bonacich centrality. It is further evident that as $\theta$ increases in value, the equilibrium risk prevention investment of the port increases and decreases as the unit investment cost increases. In addition, the aggregate risk prevention investment in the equilibrium state is 3533.406, and the number of network participants is 126. After eliminating half of the participants, the aggregate risk prevention investment in the equilibrium state is 2372.328, which indicates that the overall risk prevention investment in the equilibrium state is positively correlated with network density. These results are consistent with the conclusions in Section 3. 
Table 3 The equilibrium risk prevention investment of ports

\begin{tabular}{|l|c|c|c|}
\hline Port & $\theta=\mathbf{0 . 0 0 8}$ & $\theta=\mathbf{0 . 0 1 2}$ & $\theta=\mathbf{0 . 0 1 2}, d_{i} \uparrow$ \\
\hline Dalian Port & 5.013 & 34.693 & 18.231 \\
\hline Dandong Port & 5.777 & 34.507 & 18.251 \\
\hline Yingkou Port & 5.467 & 33.840 & 17.920 \\
\hline Panjin Port & 5.912 & 34.863 & 18.431 \\
\hline Jinzhou Port & 5.874 & 34.901 & 18.451 \\
\hline Huludao Port & 5.463 & 31.134 & 16.532 \\
\hline
\end{tabular}

Table 4 illustrates the port risk prevention investment subsidy at different $\theta$ values with a maximum aggregate network utility. Furthermore, Table 4 indicates there exists a positive correlation with $\theta$.

Table 4 The subsidy of ports under maximum aggregate network utility

\begin{tabular}{|l|c|c|}
\hline Port & $\theta=\mathbf{0 . 0 0 8}$ & $\theta=\mathbf{0 . 0 1 2}$ \\
\hline Dalian Port & 100.318 & 561.553 \\
\hline Dandong Port & 97.145 & 543.602 \\
\hline Yingkou Port & 96.013 & 536.882 \\
\hline Panjin Port & 97.794 & 547.717 \\
\hline Jinzhou Port & 98.060 & 549.145 \\
\hline Huludao Port & 86.991 & 485.835 \\
\hline
\end{tabular}

(2) The identification and ranking of key nodes in PHSN. Due to the substantial amount of data, we only display the first 20 data, and the specific results are presented. Several conclusions can be drawn from further analysis of the results. (a) The importance of ports, nodes in the hinterlands and logistics enterprises to the service network decreases in turn. (b) The importance of hinterland nodes in Heilongjiang, Jilin and Liaoning provinces to the service network decreases in turn, and each provincial capital's importance is higher than in other cities. This is because of the location of the provinces and ports. From the perspective of aggregate network utility, to ensure the stability of the entire services network, the importance of the nodes in the hinterlands far from the ports increases correspondingly. (c) Because the importance of nodes is not only reflected in their own characteristics, but it also includes its network utility, the importance of some edge nodes in the network will increase, such as Dandong Port, Harbin and Changchun. (d) The importance of logistics enterprises is positively correlated with their position and strength.

Table 5 The overall ranking of nodes in the PHSN

\begin{tabular}{|l|l|l|l|l|l|}
\hline Value & Node & Value & Node & Value & Node \\
\hline 48.75 & Dalian Port & -9.85 & Dandong Port & -15.67 & Jixi \\
\hline 36.93 & Yingkou Port & -9.86 & Daqing & -15.79 & Qiqihar \\
\hline 19.38 & Panjin Port & -10.19 & Qitaihe & -16.25 & Shuangyashan \\
\hline 10.32 & Jinzhou Port & -11.63 & Yichun & -16.81 & $\begin{array}{l}\text { Dalian Inland Port Logistics Base } \\
\text { Co. LTD }\end{array}$ \\
\hline-0.83 & Harbin & -11.75 & Hegang & -17.08 & Changbaishan \\
\hline-3.04 & Changchun & -13.7 & Mudanjiang & -17.11 & Tonghua \\
\hline-9.43 & Suihua & -13.88 & Jilin & & \\
\hline
\end{tabular}


Table 6 The ranking of nodes in the hinterlands

\begin{tabular}{|l|l|l|l|l|l|}
\hline Value & Node & Value & Node & Value & Node \\
\hline-0.83 & Harbin & -13.7 & Mudanjiang & -17.11 & Songyuan \\
\hline-3.04 & Changchun & -13.88 & Jilin & -18.31 & Jiamusi \\
\hline-9.43 & Suihua & -15.67 & Jixi & -18.63 & Heihe \\
\hline-9.86 & Daqing & -15.79 & Qiqihar & -20.3 & Daxinganling \\
\hline-10.19 & Qitaihe & -16.25 & Shuangyashan & -25.57 & Baicheng \\
\hline-11.63 & Yichun & -17.08 & Changbaishan & -31.33 & Siping \\
\hline-11.75 & Hegang & -17.11 & Tonghua & & \\
\hline
\end{tabular}

Table 7 The ranking of ports

\begin{tabular}{|l|l|l|l|}
\hline Value & Node & Value & Node \\
\hline 48.75 & Dalian Port & 10.32 & Jinzhou Port \\
\hline 36.93 & Yingkou Port & -9.85 & Dandong Port \\
\hline 19.38 & Panjin Port & -34.86 & Huludao Port \\
\hline
\end{tabular}

Table 8 The ranking of logistic enterprises

\begin{tabular}{|l|l|l|l|}
\hline Value & \multicolumn{1}{|c|}{ Node } & Value & \multicolumn{1}{|c|}{ Node } \\
\hline-16.81 & PDA & -26.57 & Dalian Heishan Logistics Co. LTD \\
\hline-18.41 & COFCO & -26.7 & Beidahuang Logistics Co. LTD \\
\hline-21.33 & Dalian Port Jifa Logistics Co. LTD & -26.81 & $\begin{array}{l}\text { Panjin Liaobin Xincheng Logistics Co. } \\
\text { LTD }\end{array}$ \\
\hline-23.07 & $\begin{array}{l}\text { Yingkou Chenguang Logistics } \\
\text { Co. LTD }\end{array}$ & -27.01 & China Logistics Liaoning Co. LTD \\
\hline-23.27 & CRCT & -27.11 & Dalian Container Logistics Co. LTD \\
\hline-24.53 & Dalian Burton Logistics Co. LTD & -27.28 & $\begin{array}{l}\text { Dalian International Logistics Park } \\
\text { Development Co. LTD }\end{array}$ \\
\hline-24.73 & JCtrans & -27.43 & CRT \\
\hline-25.14 & $\begin{array}{l}\text { Dalian Port Wantong Logistics Co. } \\
\text { LTD }\end{array}$ & -27.67 & Panther Logistics Co. LTD \\
\hline-25.64 & $\begin{array}{l}\text { Yingkou Coastal Industrial } \\
\text { Logistics Base Co. LTD }\end{array}$ & -27.7 & $\begin{array}{l}\text { China Silk Liaoning Chemical } \\
\text { Logistics Co. LTD }\end{array}$ \\
\hline-25.91 & $\begin{array}{l}\text { Liaoning Zhongyun Logistics Co. } \\
\text { LTD }\end{array}$ & -27.81 & $\begin{array}{l}\text { Dalian Cosco Marine Logistics Co. } \\
\text { LTD }\end{array}$ \\
\hline
\end{tabular}

(3) The identification and ranking of the key groups in the PHSN. To save the calculation time of key groups, this paper uses the size two group as an example. The specific results are presented in Table 9. 
Table 9 The overall ranking of key groups

\begin{tabular}{|l|l|l|l|l|l|}
\hline Group & Value & \multicolumn{2}{|c|}{ Group } & Value \\
\hline $\begin{array}{l}\text { Harbin Railway } \\
\text { Logistics Co. LTD }\end{array}$ & Dalian Port & -778.39 & $\begin{array}{l}\text { Heilongjiang } \\
\text { Anlutong Logistics } \\
\text { Co. LTD }\end{array}$ & Huludao Port & -890.25 \\
\hline $\begin{array}{l}\text { Harbin Railway } \\
\text { Logistics Co. LTD }\end{array}$ & Jinzhou Port & -793.22 & Dalian Port & Jinzhou Port & -893.99 \\
\hline $\begin{array}{l}\text { Heilongjiang } \\
\begin{array}{l}\text { Anlutong Logistics } \\
\text { Co. LTD }\end{array}\end{array}$ & Panjin Port & -794.53 & Dandong Port & Yingkou Port & -894.8 \\
\hline $\begin{array}{l}\text { Heilongjiang } \\
\text { Anlutong Logistics } \\
\text { Co. LTD }\end{array}$ & Dandong Port & -805.5 & Dalian Port & Panjin Port & -896.11 \\
\hline $\begin{array}{l}\text { Heilongjiang } \\
\text { Anlutong Logistics } \\
\text { Co. LTD }\end{array}$ & Yingkou Port & -806.25 & Dalian Port & Dandong Port & -904.35 \\
\hline Yingkou Port & Panjin Port & -869.27 & Dalian Port & Yingkou Port & -906.21 \\
\hline Yingkou Port & Jinzhou Port & -872.33 & Jiamusi & Dalian Port & -933.2 \\
\hline Panjin Port & Jinzhou Port & -873.07 & Suihua & Dalian Port & -937.8 \\
\hline Dandong Port & Jinzhou Port & -885.17 & Heihe & Dalian Port & -939.71 \\
\hline Dandong Port & Panjin Port & -886.82 & Daqing & Dalian Port & -942.53 \\
\hline
\end{tabular}

(4) Comparative analysis of subsidy strategies. Allocating the limited resources to risks according to the importance of nodes and groups in the network under the constraints of resources, target risks and efficiency greatly improve the efficiency of risk prevention investment. We next illustrate the advantages of these two strategies based on the identification of key nodes and key groups. The optimal subsidy under targeted subsidy strategy is $s_{i}^{*}=\theta \sum_{j=1}^{n} g_{i j} v_{j}$ and is computed in Section 4. We select the top 20 nodes from the ranked key nodes. For consistency in comparisons, the top 10 groups from the ranked key groups are selected, and the selected key nodes and groups are subsidized in order.

Fig. 4, which illustrates the aggregate subsidy utility growth curve, indicates that the aggregate utility produced by subsidizing each node among 20 key nodes is higher than that among 20 random nodes. In the initial stage, the difference between the aggregate utility produced by key nodes and that by random nodes is narrow, but with a sustaining subsidy that difference increases due to network complementary utility. Accordingly, the advantage of the key node subsidy strategy is evident. 


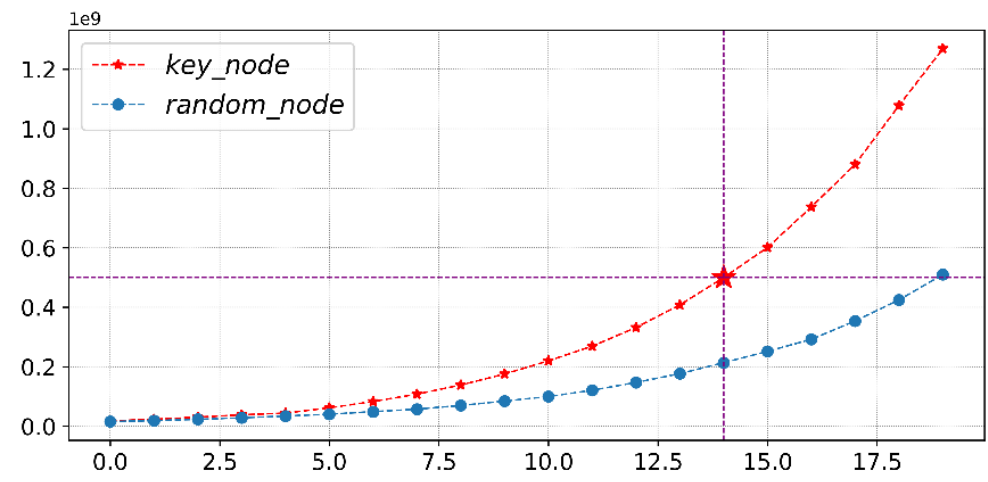

Fig. 4 The utility comparison between key nodes and random nodes subsidy strategies

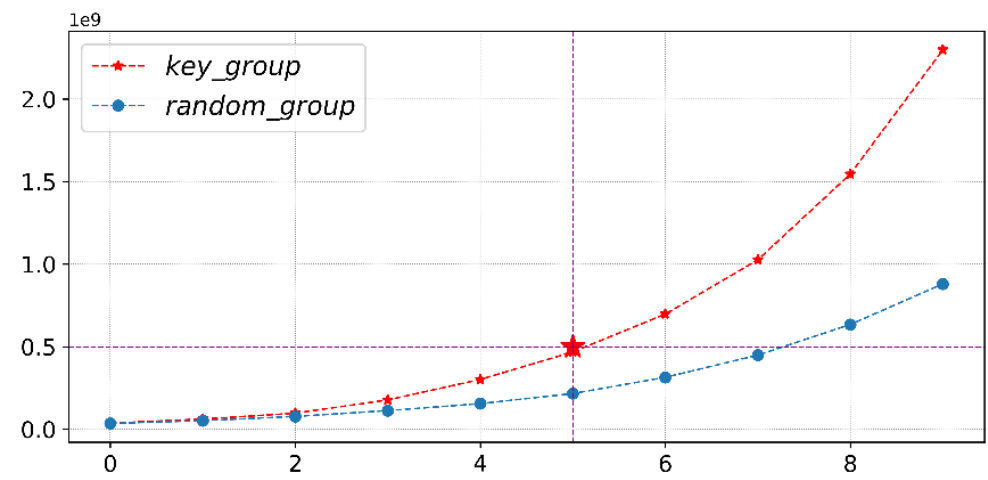

Fig. 5 The utility comparison between key groups and random groups subsidy strategies

The curves in Fig. 5 exhibit characteristics similar to the curves in Fig. 4, i.e., the utility difference broadens with the sustaining subsidy. When comparing Fig. 4 and Fig. 5 and setting 0.5 as the target, the key nodes subsidy strategy reaches the target after subsidizing 14 nodes, while the key group subsidy achieves the target only after subsidizing 5 groups, i.e., 10 nodes. This finding illustrates that key group subsidy has more advantages than the key nodes subsidy with respect to efficiency. In addition, the aggregate utility of the key group subsidy after subsidizing 10 groups is 2.1 , while the utility of the key nodes subsidy is only 1.3 , which indicates that the complementary utility of the key group subsidy is better than that of the key nodes subsidy. Accordingly, it is concluded that the key group subsidy is superior to the key nodes subsidy.

\section{Conclusions}

This study analyzes the risk prevention investment strategy and subsidy strategies of a port-hinterland service network that consists of ports, carriers, and nodes in the hinterlands. Furthermore, the study validates the model through a case analysis that provides a new perspective of risk prevention for relevant participants and managers. This study yields several conclusions.

(1) Participants' risk prevention investment strategies are closely related to their KatzBonacich centrality, which increases as the interaction intensity increases and decreases as the unit risk prevention investment cost the increases.

(2) In the equilibrium state, the aggregate risk prevention investment of port-hinterland service network increases as the network density increases.

(3) The optimal risk prevention investment of the participants in the port-hinterland service network is positively correlated with the maximum competitive intensity of the service network. 
(4) Homogeneous subsidies for risk prevention investment cannot increase the overall network risk prevention utility level.

(5) In the case of resource and efficiency constraints, without considering the cost of acquiring port-hinterland service network information, the key node subsidy strategy is better than the random node subsidy strategy, while the key group subsidy strategy has greater advantages than the key node subsidy strategy, whose advantages are primarily specific to the efficiency and complementary utility.

From the abovementioned conclusions, several policy implications can be suggested for the managers or the government. (1) Improve the cooperation relationships between different kinds of agents in the PHSN. Because the optimal risk prevention investment is positively correlated with the maximum competitive intensity of a service network, so this policy can enhances the risk prevention ability and can obtain the higher risk prevention utility using lower amount of investment with the mitigation of competition intensity; (2) Merge the service agent with lower risk resistance ability or service capability. This strategy can lower the number of service agent and form lots of integrated service agents with higher service capability and risk resistance ability, which to some extent improves the risk resistance ability and reduces the risk prevention cost. (3) Adopt the differentiated subsidy policy. Making targeted risk prevention investment subsidy for different service nodes or service groups by recognizing their importance to a PHSN can improve the risk prevention efficiency under the resource or time limitation.

The analyses discussed herein provide risk prevention references for managers of and participants in the port-hinterland service network, thus enhancing, to some extent, the risk prevention ability of the network. However, some aspects of the study require further examination. In a future research, we will extend our model by considering the special attributes of the participants, the differences in relations and other perspectives to improve feasibility of our findings. In addition, the time dimension of risk prevention is an aspect that should be the subject of further study.

\section{ACKNOWLEDGEMENTS}

This work was supported by the National Key Research and Development Project (Grant No.2019YFB1600401), Youth Program of National Natural Science Foundation of China (Grant No. 71503029) and the State Key Program of National Natural Science of China (Grant No.71831002).

\section{REFERENCES}

[1] Chen H, Lam J S L, Liu N. Strategic investment in enhancing port-hinterland container transportation network resilience: A network game theory approach. Transportation Research Part B: Methodological. 2018, 111, 83-112. https://doi.org/10.1016/j.trb.2018.03.004

[2] Jiang B, Li J, Shen S. Supply Chain Risk Assessment and Control of Port Enterprises: Qingdao port as case study. The Asian Journal of Shipping and Logistics. 2018, 34, 198-208. https://doi.org/10.1016/j.ajsl.2018.09.003

[3] Michail N A, Melas K D. Shipping markets in turmoil: An analysis of the Covid-19 outbreak and its implications. Transportation Research Interdisciplinary Perspectives. 2020, 7, 100-178. https://doi.org/10.1016/j.trip.2020.100178

[4] Qu C, Wang G W Y, Zeng Q. Modelling port subsidy policies considering pricing decisions of feeder carriers. Transportation Research Part E: Logistics and Transportation Review. 2017, 99, 115-133. https://doi.org/10.1016/j.tre.2017.01.004

[5] Liu J, Wang J. Carrier alliance incentive analysis and coordination in a maritime transport chain based on 
service competition. Transportation Research Part E: Logistics and Transportation Review. 2019, 128, 333-355. https://doi.org/10.1016/j.tre.2019.06.009

[6] Lai X, Tao Y, Wang F, et al. Sustainability investment in maritime supply chain with risk behavior and information sharing. International Journal of Production Economics. 2019, 218, 16-29. https://doi.org/10.1016/j.ijpe.2019.02.021

[7] Tan Z, Meng Q, Wang F, et al. Strategic integration of the inland port and shipping service for the ocean carrier. Transportation Research Part E: Logistics and Transportation Review. 2018, 110, 90-109. https://doi.org/10.1016/j.tre.2017.12.010

[8] álvarez-Sanjaime Ó, Cantos-Sánchez P, Moner-Colonques R, et al. The impact on port competition of the integration of port and inland transport services. Transportation Research Part B: Methodological. 2015, 80, 291-302. https://doi.org/10.1016/j.trb.2015.07.011

[9] Talley W K, Ng M. Hinterland transport chains: A behavioral examination approach. Transportation Research Part E: Logistics and Transportation Review. 2018, 113, 94-98. https://doi.org/10.1016/j.tre.2018.03.001

[10] Talley W K, Ng M. Hinterland transport chains: Determinant effects on chain choice. International Journal of Production Economics. 2017, 185, 175-179. https://doi.org/10.1016/j.ijpe.2016.12.026

[11] Goerlandt F, Montewka J. Maritime transportation risk analysis: Review and analysis in light of some foundational issues. Reliability Engineering \& System Safety. 2015, 138, 115-134. https://doi.org/10.1016/j.ress.2015.01.025

[12] Loh H S, Zhou Q, Thai V V, et al. Fuzzy comprehensive evaluation of port-centric supply chain disruption threats. Ocean \& Coastal Management. 2017, 148, 53-62. https://doi.org/10.1016/j.ocecoaman.2017.07.017

[13] Vilko J, Ritala P, Hallikas J. Risk management abilities in multimodal maritime supply chains: Visibility and control perspectives. Accident Analysis \& Prevention. 2016, 1-13.

[14] Asadabadi A, Miller-Hooks E. Maritime port network resiliency and reliability through co-opetition. Transportation Research Part E: Logistics and Transportation Review. 2020, 137, 101916. https://doi.org/10.1016/j.tre.2020.101916

[15] Hosseini S, Barker K. Modeling infrastructure resilience using Bayesian networks: A case study of inland waterway ports. Computers \& Industrial Engineering. 2016, 93, 252-266. https://doi.org/10.1016/j.cie.2016.01.007

[16] Salehi Sadghiani N, Torabi S A, Sahebjamnia N. Retail supply chain network design under operational and disruption risks. Transportation Research Part E: Logistics and Transportation Review. 2015, 75, 95114. https://doi.org/10.1016/j.tre.2014.12.015

[17] Goldbeck N, Angeloudis P, Ochieng W. Optimal supply chain resilience with consideration of failure propagation and repair logistics. Transportation Research Part E: Logistics and Transportation Review. 2020, 133, 101830. https://doi.org/10.1016/j.tre.2019.101830

[18] Zhu S, Zheng S, Ge Y, et al. Vertical integration and its implications to port expansion. Maritime Policy \& Management. 2019, 46, 920-938. https://doi.org/10.1080/03088839.2019.1594426

[19] Koh Y. Optimal investment priority in container port development. Maritime Policy \& Management. 2014, 2, 109-123. https://doi.org/10.1080/03088830117187

[20] Luo M, Liu L, Gao F. Post-entry container port capacity expansion. Transportation Research Part B: Methodological. 2012, 46, 120-138. https://doi.org/10.1016/j.trb.2011.09.001

[21] Zhuang W, Luo M, Fu X. A game theory analysis of port specialization-implications to the Chinese port industry. Maritime Policy \& Management: IAME 2012, ALRT and IFSPA 2013. 2014, 41, 268-287. https://doi.org/10.1080/03088839.2013.839517

[22] Wan Y, Basso L J, Zhang A. Strategic investments in accessibility under port competition and interregional coordination. Transportation Research Part B: Methodological. 2016, 93, 102-125. https://doi.org/10.1016/j.trb.2016.07.011

[23] Balliauw M, Kort P M, Meersman H, et al. The case of public and private ports with two actors: Capacity investment decisions under congestion and uncertainty. Case Studies on Transport Policy. 2020, 8, 403415. https://doi.org/10.1016/j.cstp.2019.03.009

[24] Asadabadi A, Miller-Hooks E. Maritime port network resiliency and reliability through co-opetition. Transportation Research Part E: Logistics and Transportation Review. 2020, 137, 101916. https://doi.org/10.1016/j.tre.2020.101916 
[25] Chen H, Liu S. Should ports expand their facilities under congestion and uncertainty?. Transportation Research Part B: Methodological. 2016, 85, 109-131. https://doi.org/10.1016/j.trb.2015.12.018

[26] Doan X V, Shaw D. Resource allocation when planning for simultaneous disasters. European Journal of Operational Research. 2019, 274, 687-709. https://doi.org/10.1016/j.ejor.2018.10.015

[27] Su Z, Zhang G, Liu Y, et al. Multiple emergency resource allocation for concurrent incidents in natural disasters. International Journal of Disaster Risk Reduction. 2016, 17, 199-212. https://doi.org/10.1016/j.ijdrr.2016.05.003

[28] Rezapour S, Naderi N, Morshedlou N, et al. Optimal deployment of emergency resources in sudden onset disasters. International Journal of Production Economics. 2018, 204, 365-382. https://doi.org/10.1016/j.ijpe.2018.08.014

[29] Liu N, Gong Z, Xiao X. Disaster prevention and strategic investment for multiple ports in a region: cooperation or not. Maritime Policy \& Management. 2018, 45, 585-603. https://doi.org/10.1080/03088839.2018.1454991

[30] Xiao Y, Fu X, Ng A K Y, et al. Port investments on coastal and marine disasters prevention: Economic modeling and implications. Transportation Research Part B: Methodological. 2015, 78, 202-221. https://doi.org/10.1016/j.trb.2015.04.009

[31] Gong L, Xiao Y, Jiang C, et al. Seaport investments in capacity and natural disaster prevention. Transportation Research Part D: Transport and Environment. 2020, 85, 102367. https://doi.org/10.1016/j.trd.2020.102367

[32] Xiao Y, Fu X, Ng A K Y, et al. Port investments on coastal and marine disasters prevention: Economic modeling and implications. Transportation Research Part B: Methodological. 2015, 78, 202-221. https://doi.org/10.1016/j.trb.2015.04.009

[33] Randrianarisoa L M, Zhang A. Adaptation to climate change effects and competition between ports: Invest now or later?. Transportation Research Part B: Methodological. 2019, 123,279-322. https://doi.org/10.1016/j.trb.2019.03.016

[34] Ballester. WHOS WHO IN NETWORKS WANTEDTHE KEY PLAYER. Econometrica. 2006, 74, 1403-1417. https://doi.org/10.1111/j.1468-0262.2006.00709.X

[35] Michael D. K Onig X L Y Z. R\&D Networks: Theory, Empirics and Policy Implications. Social ence Electronic Publishing. 2014, 101, 476-491. https://doi.org/10.1162/rest_a_00762

[36] Helsley R W, Zenou Y. Social networks and interactions in cities. Journal of Economic Theory. 2014, 150, 426-466. https://doi.org/10.1016/j.jet.2013.09.009

[37] Coralio Ballester A C Y Z. Who's Who in Crime Networks: Wanted - The Key Player. Econometrica. 2006, 74, 1403-1417. https://doi.org/10.1111/j.1468-0262.2006.00709.x

[38] König M D, Tessone C J, Zenou Y. Nestedness in networks: A theoretical model and some applications. Theoretical Economics. 2014, 9, 695-752. https://doi.org/10.3982/TE1348

[39] Bonacich P. Factoring and weighting approaches to status scores and clique identification. The Journal of Mathematical Sociology. 1972, 2, 113-120. https://doi.org/10.1080/0022250X.1972.9989806

[40] Dov Monderer, Lloyd S. Shapley. Potential Games. GAMES AND ECONOMIC BEHAVIOR. 1996, 44, 124-143. https://doi.org/10.1006/game.1996.0044

Submitted: $\quad$ 04.01.2021. Z Zhang Pengfei ${ }^{1,3}$, haerbinzpf@163.com

Han Bing ${ }^{1,2}$, hanbing0610@163.com

Accepted: $\quad$ 09.03.2021. Kuang Haibo ${ }^{1,2}$, khb@dlmu.edu.cn

${ }^{1}$ Collaborative Innovation Center for Transport Studies, Dalian Maritime University, Dalian 116026, China;

${ }^{2}$ Shipping Economics and Management College, Dalian Maritime University, Dalian 116026 China;

${ }^{3}$ Transportation Engineering College, Dalian Maritime University, Dalian 116026, China 